\title{
PENGATURAN KESEIMBANGAN PENGISIAN DAN PENGOSONGAN BATERAI ASAM TIMBAL
}

\author{
Mochammad Rismansyah dan Refdinal Nazir \\ Jurusan Teknik Elektro, Fakultas Teknik, Universitas Andalas \\ *Corresponding author, e-mail : rismanajah@yahoo.com
}

\begin{abstract}
Abstrak-Dalam tulisan ini diusulkan suatu sistem pengaturan keseimbangan pengisian (charging) dan pengosongan (discharging) pada baterai asam timbal menggunakan mikrokontroler arduino uno $16 \mathrm{U} 2$. Perhitungan kapasitas baterai menggunakan metoda As (Ampere-second). Sebelum sistem ini dijalankan, nilai energi yang tersimpan pada baterai dihitung menggunakan hubungan antara kapasitas baterai (SOC) dan tegangan open circuit baterai. Mikrokontroler akan melakukan perhitungan selama sistem berjalan menggunakan hubungan setiap arus pada sistem. Pengaturan dipisahkan antara pengaturan titik maksimal baterai dan titik minimal baterai. Pengaturan titik maksimal menjaga baterai dari kelebihan pengisian. Saat baterai telah penuh maka arus peluahan/pembuangan akan mengalir yang mencegah baterai mengalami pengisian saat mencapai titik maksimum. Arus pembuangan diset konstan 0.153 A. Pengaturan titik minimum menjaga baterai dari kekosongan (kekurangan energi). Beban tidak akan mendapatkan pasokan energi baik dari charger maupun baterai saat baterai dibawah titik minimumnya karena charger hanya melakukan pengisian pada baterai hingga melewati titik minimumnya. Sistem ini menggunakan titik minimum $11.67 \%$ dengan kapasitas baterai $50 \mathrm{Ah}$. Sistem pengaturan yang dibuat telah berhasil menjaga baterai dari kondisi kelebihan muatan dan kekurangan muatan.
\end{abstract}

Kata Kunci : Baterai asam timbal, mosfet, pengisian dan peluahan, mikrokontroler arduino uno

\begin{abstract}
In this paper proposed a system of balance settings for charging and discharging the lead-acid battery using a microcontroller arduino uno 16U2. The calculation of battery capacity using the method of As (Ampere-second). Before this is done, the value of the energy stored in the battery is calculated using the relationship between the battery capacity (SOC) and the open-circuit voltage of the battery. The microcontroller will do the calculations for the system running using any current relationships in the system. Settings are separated between setting the maximum point and minimum point battery battery. Setting the maximum point guard of excess charging batteries. When the battery is full, the current discharge / disposal will flow which prevents the battery charging when it reaches the maximum point. 0153 constant exhaust flow set point A. Setting minimum keep the battery from the void (lack of energy). Load will not get a good supply of energy or battery charger when the battery below the minimum point because the charger is only charging the battery to pass the minimum point. This system uses the point of $11.67 \%$ with a minimum capacity of $50 \mathrm{Ah}$ battery. System settings are made has managed to keep the battery from overload conditions and under loading.
\end{abstract}

Keywords : Lead-acid Battery, mosfet, charging and discharging, arduino uno microcontroller

Copyright $@ 2016$ JNTE. All rights reserved

\section{PENDAHULUAN}

Pembangkit listrik dengan sumber energi terbarukan saat ini semakin berkembang digunakan untuk penyediaan energi listrik pedesaan ataupun rumah tangga. Salah satu contoh yang banyak dikembangkan yaitu Pembangkit Listrik Tenaga Mikrohidro (PLTMh). Daya yang dibangkitkan oleh PLTMh harus dapat memenuhi beban puncak dan relatif konstan. Pola beban rumah tangga bervariasi dan beban puncak hanya terjadi pada waktu malam hari. Sedangkan pembangkit akan memasok energi selama 24 jam dalam daya yang relatif konstan. Untuk memanfaat kelebihan energi listrik selama diluar beban pucak, baterai dapat digunakan sebagai penyimpan dan digunakan sebagai energi cadangan[1]. Oleh karena itu, pengaturan keseimbangan pengisian dan pengosongan baterai menarik dikaji dalam pengimplementasian pada sistem PLTMh. 
Kajian mengenai monitoring kinerja baterai asam timbal telah dilakukan untuk membandingkan kondisi baterai pada pengujian dan simulasi menggunakan Matlab. Monitoring yang dilakukan yaitu menentukan grafik tegangan, arus, dan $\mathrm{SoC}$ baterai asam timbal. Monitoring yang dilakukan membandingkan hasil pengujian dan hasil simulasi. Sehingga pembacaan parameter baterai seperti tegangan, arus, dan SoC akan terlihat dimonitor computer laptop [2]. Penelitian lainnya juga dilakukan mengenai perancangan sistem proteksi untuk menghindari kelebihan muatan baterai. Penelitian ini berhasil memproteksi baterai asam timbal dari kelebihan pengisian dengan menggunakan sistem pembuangan. Mikrokontroler akan membaca tegangan baterai untuk menentukan baterai penuh. Baterai akan melakukan pembuangan saat mikrokontroler membaca baterai telah penuh. Pembuangan dilakukan dengan mengalirkan arus baterai menuju resistor batu [3].

Dalam tulisan ini diusulkan suatu sistem pengaturan keseimbangan pengisian (charging) dan pengosongan (discharging) pada baterai asam timbal. Pengaturan yang dilakukan akan menjaga keseimbangan baterai dari pengisian dan pengosongan. Pengaturan pengisian akan menjaga baterai dari kekosongan muatan dengan menjaga baterai dari beban. Pengaturan pengosongan akan menjaga baterai dari kelebihan muatan dengan membuang muatan ke resistor pembuangan.

\section{BATERAI ASAM TIMBAL}

Semua baterai asam timbal beroperasi dengan reaksi dasar yang sama. Saat baterai melepaskan muatan, material aktif pada elektroda bereaksi dengan elektrolit membentuk timbal sulfat $\left(\mathrm{PbSO}_{4}\right)$ dan air $\left(\mathrm{H}_{2} \mathrm{O}\right)$. Saat pengisian muatan timbal sulfat berubah kembali menjadi timbal dioksida pada elektroda positif dan timbal pada elektroda negatif, dan ion sulfat $\left(\mathrm{SO}_{4}{ }^{2-}\right)$ kembali menjadi larutan elektrolit membentuk asam sulfat [4].

\subsection{Reaksi Pada Baterai Asam Timbal}

1. Reaksi Pada PengosonganBaterai [4] Pada proses pengosongan terjadi reaksi :

a. Pada elektroda negatif (Anoda)

$$
\mathrm{Pb}+\mathrm{HSO}_{4}^{-}-2 \mathrm{e}^{-} \rightarrow \mathrm{PbSO}_{4}+\mathrm{H}^{+}
$$

b. Pada elektroda positif (Katoda)

$$
\mathrm{PbO}_{2}+\mathrm{HSO}_{4}^{-}+3 \mathrm{H}^{+}+2 \mathrm{e}^{-} \rightarrow \mathrm{PbSO}_{4}+2 \mathrm{H}_{2} \mathrm{O}
$$

2. Reaksi Pada Pengisian Baterai [4] Pada proses pengisian terjadi reaksi :

a. Pada Elektroda Positif (Anoda)

$$
\mathrm{PbSO}_{4}+2 \mathrm{H}_{2} \mathrm{O}-2 \mathrm{e}^{-} \rightarrow \mathrm{PbO}_{2}+\mathrm{HSO}_{4}^{-}+3 \mathrm{H}^{+}
$$

b. Pada Elektroda Negatif (Katoda)

$$
\mathrm{PbSO}_{4}+\mathrm{H}^{+}+2 \mathrm{e}^{-} \rightarrow \mathrm{Pb}+\mathrm{HSO}_{4}^{-}
$$

\subsection{State of Charge (SoC)}

State of Charge merupakan besaran yang digunakan untuk mengetahui kondisi pengisian baterai berdasarkan hubungan antara tegangan open circuit baterai $\left(V_{\mathrm{oc}}\right)$ dengan kapasitas baterai (Ah) seperti ditunjukkan oleh Gambar 2.1.

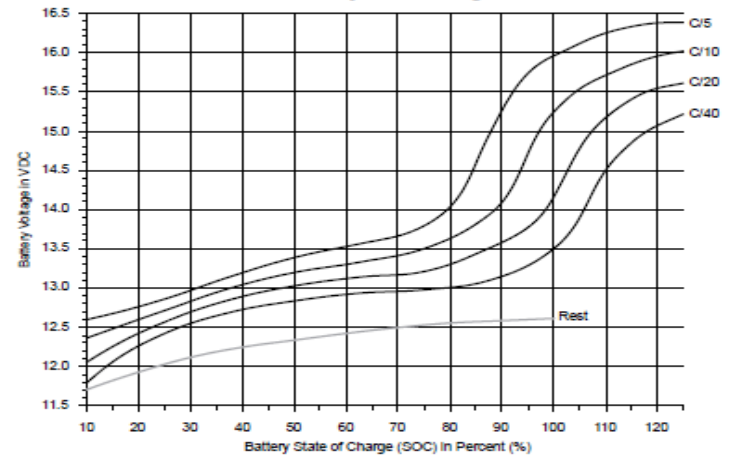

Gambar 1. Hubungan $V_{o c}$ dengan Kapasitas Baterai

Angka C/XX merupakan besaran nilai saat charging dalam ampere (C) sebanding terhadap kapasitas baterai (XX). Jika digunakan baterai dengan kapasitas $50 \mathrm{Ah}$ dan arus pengisian 2.5 A, maka kurva yang digunakan adalah kurva $\mathrm{C} / 20$ [5].

State of Charge (SOC) juga dapat didefinisikan berdasarkan persamaan berikut [6]:

$$
\operatorname{SOC}(t)=\operatorname{SOC}\left(t_{0}\right)-\frac{1}{A H C} \int_{t_{0}}^{t} i(\tau) d \tau
$$


Dimana, $\mathrm{SoC}_{(\mathrm{t})}$ merupakan $\mathrm{SoC}$ baterai pada keadaan sebelumnya, AHC adalah kapasitas baterai saat fully charged, dan $i(\tau)$ adalah arus peluahan. Selain SoC terdapat istilah lain yang berkaitan dengan kapasitas baterai yaitu SoH (State of Health). SoH dapat didefinisikan sebagai rasio antara kapasitas charge maksimum dari baterai lama $\left(\mathrm{AHC}_{(\mathrm{Aged})}\right)$ dengan kapasitas charge dari baterai baru $\left(\mathrm{AHC}_{(\mathrm{Nom})}\right)$ yang dapat dirumuskan sebagai berikut [6] :

$$
S O H=\frac{A H C_{\text {Aged }}}{A H C_{\text {Nom }}}
$$

Rangkaian ekivalen baterai dapat dilihat pada Gbr. 2.2, I menunjukkan arus baterai, OCV merupakan Open Circuit Voltage, V menunjukkan tegangan terminal baterai, $\mathrm{R}_{1}$ menyatakan resistansi internal respon cepat. $\mathrm{R}_{2}$ menyatakan resistanse internal yang merespon kapasitansi C. $\mathrm{C}$ terhubung paralel dengan $\mathrm{R}_{2}$ dan $\mathrm{C}$ memiliki waktu konstan $\tau$. Fenomena transien baterai bisa dinyatakan oleh $\mathrm{R}_{2}$ dan $\mathrm{C}$. Oleh karena itu, $\mathrm{V}$ tidak sama dengan OCV selama operasi karena parameter $\mathrm{R}_{1}, \mathrm{R}_{2}$, dan $\mathrm{C}$.

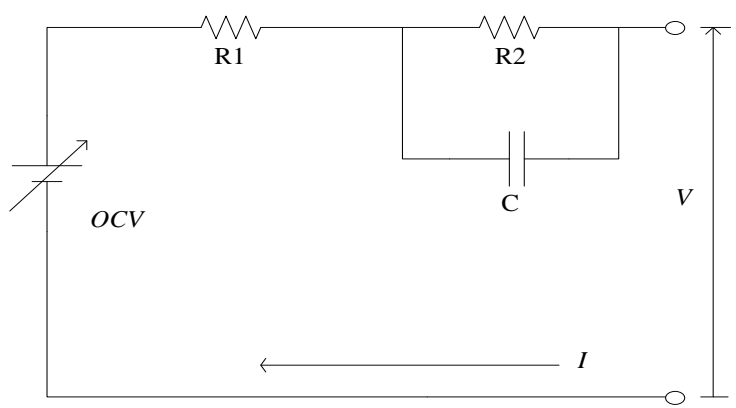

Gambar 2. Rangkaian Ekivalen Baterai [7]

Parameter rangkaian ekivalen untuk pengisian dan pengosongan memiliki nilai yang berbeda. Oleh karena itu, perbedaan parameter rangkaian ekivalen digunakan untuk pengisian dan pengosongan.Karena reaksi elektro-kimia saat pengisian dan pengosongan berbeda, sehingga hanya menjelaskan rangkaian ekivalen secara elektrikal.

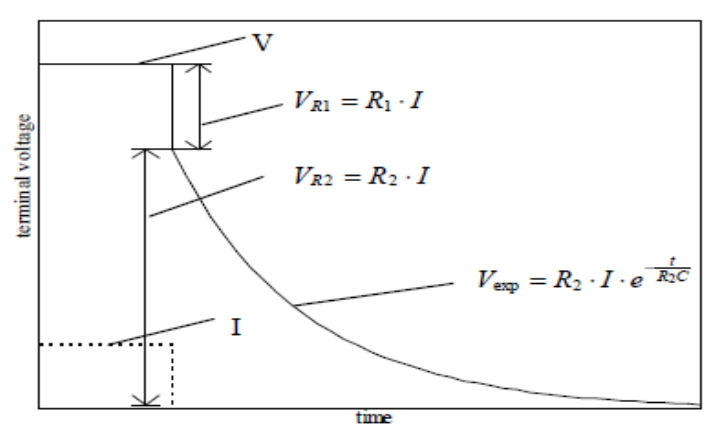

Gambar 3. Grafik Rangkaian $\mathrm{R}_{1}$ dan $\mathrm{R}_{2}$ Konstan [7]

\section{RANCANGAN SISTEM}

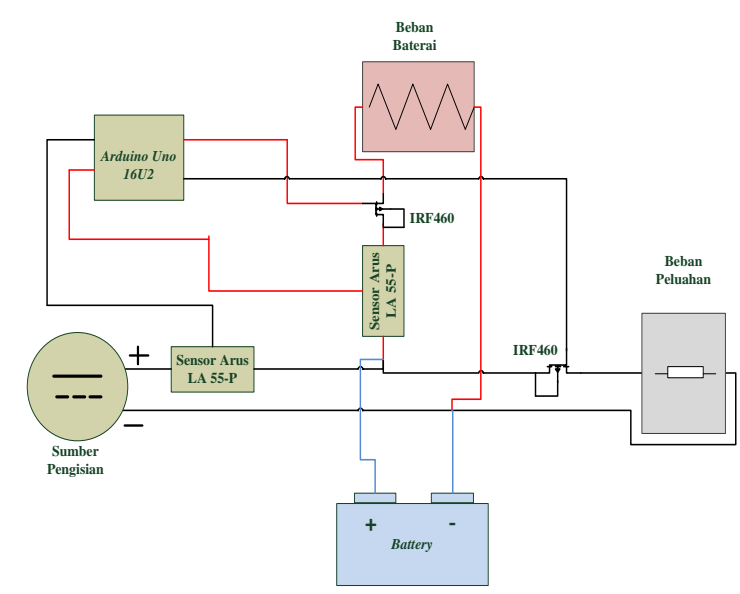

Gambar 4. Skema Umum Rancangan Sistem

Gambar di atas merupakan skema umum sistem yang diajukan. Sistem yang diajukan menggunakan beberapa komponen penting yaitu sumber pengisian, sensor arus untuk membaca arus, baterai asam timbal, beban baterai berupa lampu pijar, beban peluahan berupa beban resistif, dan mikrokotroler sebagai pusat pengaturan. Sumber pengisian akan mengalirkan daya kesistem. Pengaturan dilakukan dalam 2 tahap. Pada tahap pertama,mikontroller akan mengatur pensaklaran MOSFET dalam rangka mengatur beban peluahan. Pengaturan ini akan mengatur kondisi pengisian baterai. Apabila baterai penuh maka arus peluahan akan mengalir kebeban peluahan untuk mencegah baterai kelebihan muatan. Pada tahap kedua mikrokontroller pesaklar MOSFET dalam rangka mengatur beban baterai. Pengaturan ini akan mengatur kondisi minimum baterai. Pada 
saat titik minimum energi yang tersimpan pada baterai tidak terpenuhi maka tidak akan ada arus yang mengalir keluar baterai dan baterai terus mengalami pengisian.

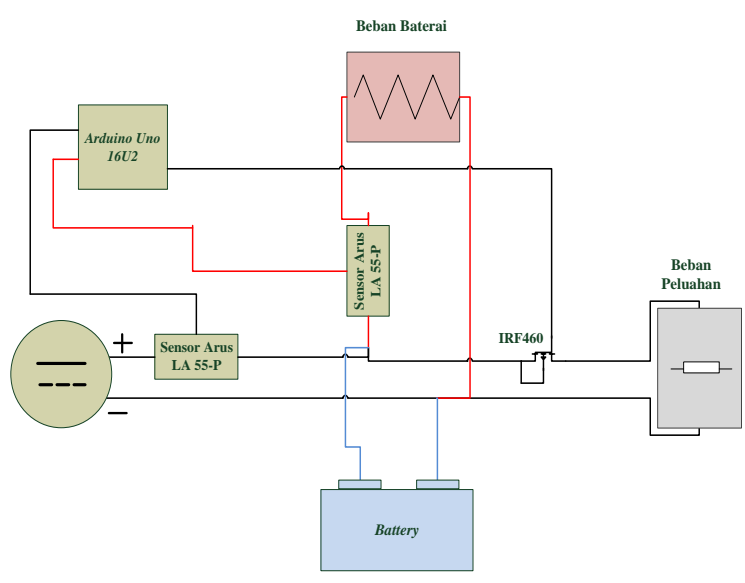

Gambar 5. Skema pengontrolan peluahan

Gambar 5 menunjukkan aliran arus pada saat proses peluahan / pembuangan. Proses pembuangan akan terjadi saat kondisi energi yang tersimpan pada baterai telah mencapai kapasitas penuh. Apabila kondisi ini tercapai maka baterai akan membuang energi yang tersimpan kebeban dan kepeluahan. Pembuangan dilakukan untuk menjaga kondisi baterai dari kelebihan penigisian.

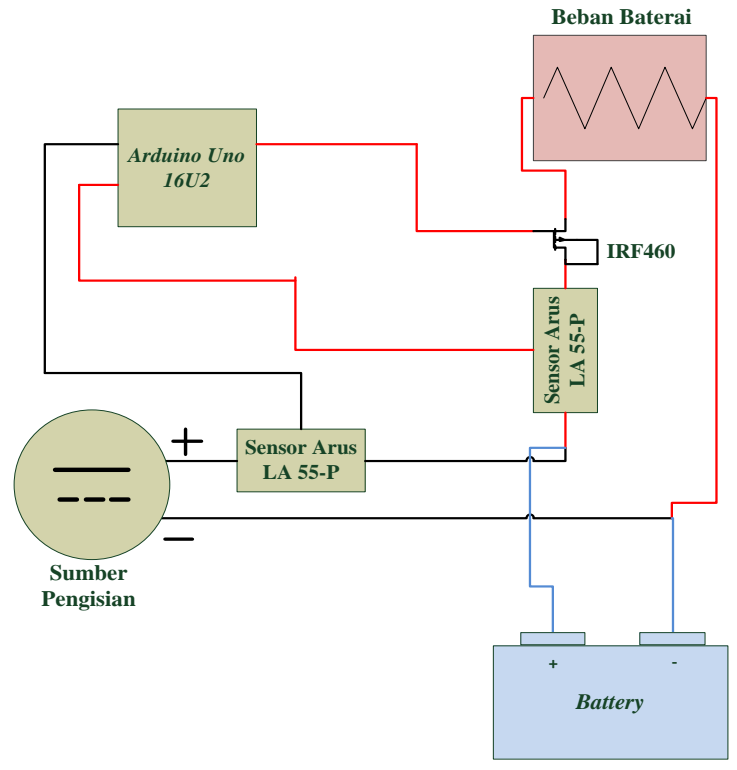

Gambar.6. Skema pengontrolan pengisian
Gambar 6 menjelaskan sistem pada saat proses charging / pengisian baterai. Proses pengisian akan terjadi apabila energi yang tersimpan pada baterai bernilai dibawah titik penuh kapasitas baterai. Hal ini berlaku dengan pengecualian bahwa charger dapat memasok beban tanpa bantuan dari baterai.

Parameter pegaturan menggunakan kapasitas baterai Ah (Ampere-Hour) yang dikonversikan menjadi As (Ampere-Second). Sehingga pembacaan energi yang tersimpan pada baterai akan dimonitor setiap detik. Pembacaan energi yang tersimpan pada baterai menggunakan 2 buah sensor arus. Sensor arus pertama untuk membaca arus input dan sensor arus kedua untuk membaca arus pengosongan. Sedangkan arus peluahan disetkonstan. Berdasarkan hukum kirchoff $(K C L)$ dapat diturunkan hubungan setiap arus sebagai berikut :

$$
I_{\text {input }}=I_{\text {charging }}+I_{\text {discharging }}+I_{\text {peluahan }} \text { (7) }
$$

Sehingga parameter pengaturan (As) dapat dihitung sebagai

$$
A s_{\text {sekarang }}=A s_{\text {sebelum }}+\left(I_{\text {char }}-I_{\text {dischar }}-I_{\text {peluahan }}\right) \Delta t
$$

As akan bertambah seiring pembacaan nilai arus charging dan akan berkurang seiring pembacaan nilai arus discharging. Sehingga energi yang tersimpan baterai dapat dimonitor secara aktual setiap detik.

\section{HASIL DAN PEMBAHASAN}

\subsection{Pengontrolan Peluahan}

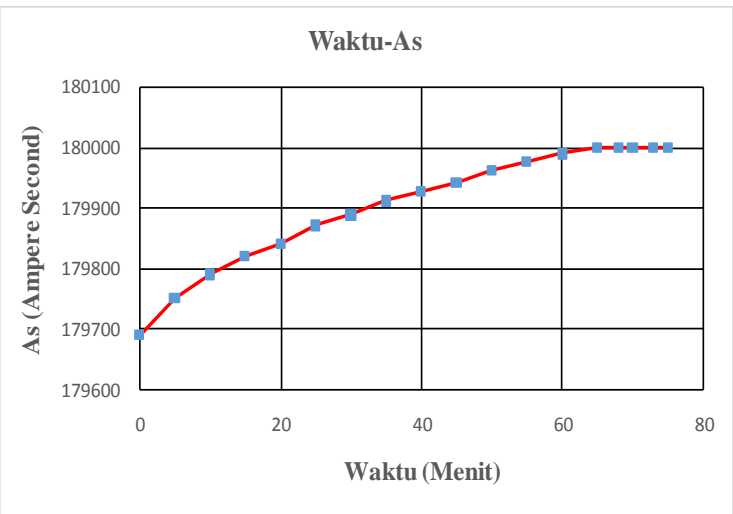

Gambar 7. Kurva energi yang tersimpan baterai (Ampere-second) terhadap waktu 


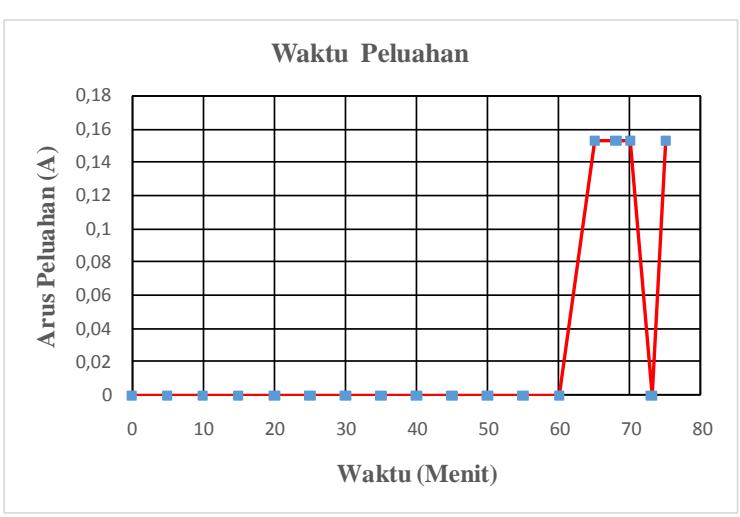

Gambar 8. Kurva Arus Peluahan terhadap Waktu

Gambar 7 \& 8 kurva menunjukan energi yang tersimpan baterai dan arus peluahan terhadap waktu. Seperti ditujukkan Gbr. 7\&8, arus peluahan akan mengalir saat energi yang tersimpan baterai telah penuh (As=180000). Baterai tidak akan meluah apabila energi yang tersimpan baterai tidak penuh. Sehingga kondisi energi yang disimpan baterai akan terjaga pada kondisi maksimal saat baterai telah penuh. Karena saat baterai mencapai titik penuh maka arus peluahan akan mengalir untuk menghindari baterai dari arus pengisian. Dari Gambar 7 terlihat bahwa baterai mencapai kondisi stabil saat arus peluahan mengalir. Sehingga energi yang tersimpan baterai dapat terjaga dari kelebihan pengisian. Pada penelitian arus peluahan diset konstan 0,153 A untuk mempermudah pengontrolan.

\subsection{Pengontrolan Pengisian Baterai}

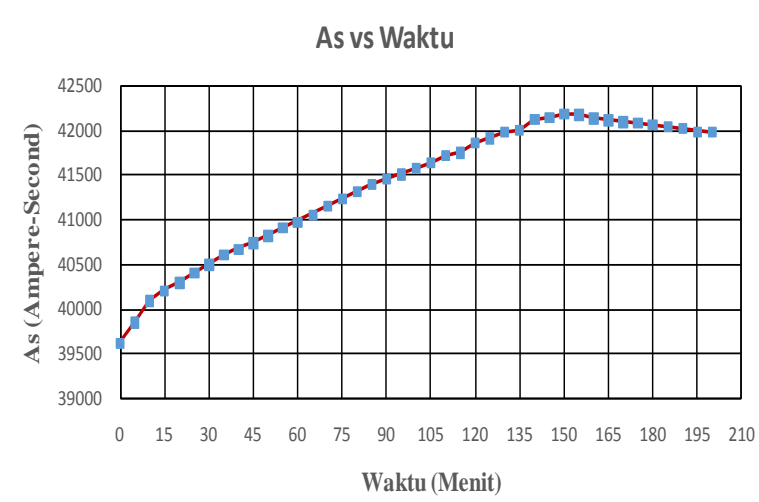

Gambar 9. Kurva energi yang tersimpan baterai (Ampere-second) terhadap waktu
Gambar 9 menunjukkan kurva energi yang tersimpan baterai terhadap waktu. Dari gambar tersebut dapat dilihat bahwa baterai terus mengalami pengisian hingga mencapai As 42000. Selama pengisian switch beban 200 watt dalam keadaan on, tetapi tidak ada arus yang mengalir kebeban karena kontrol membaca energi yang tersimpan baterai masih dibawah titik minimum untuk dibebani. Oleh karena itu PWM yang diberikan memiliki Duty cycle $0 \%$. Saat baterai mencapai titik minimum, As $=42000$, arus kebeban akan mengalir karena kontrol membaca energi yang tersimpan baterai telah cukup untuk dibebani. Dalam kajian kapasitas baterai pada titik minimum diatur $11.67 \%$. Apabila energi yang tersimpan baterai berada dibawah titik minimum tersebut, maka beban apapun yang dihubungkan tidak akan hidup hingga titik minimum baterai terpenuhi.

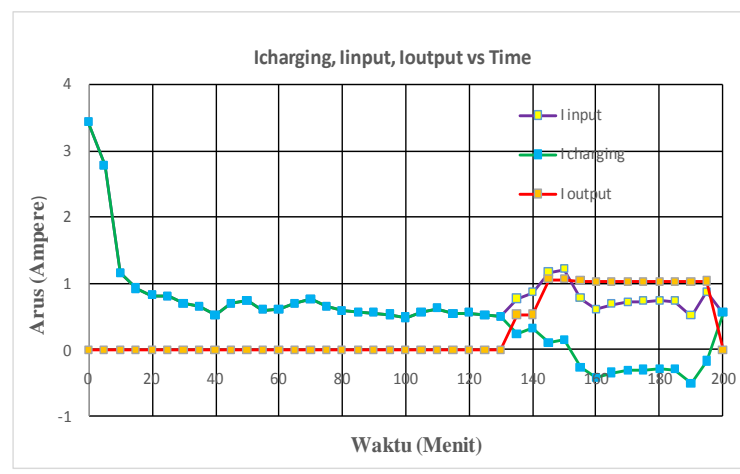

Gambar 10. Kurva Arus pengisian, arus input, dan arus output terhadap waktu

Pada Gambar 10 menunjukkan kurva hubungan arus pengisian (charging), arus input, dan arus output terhadap waktu. Dari gambar dapat dilihat bahwa selama baterai dibawah kapasitas minimumnya maka arus chargingakan sama dengan arus input. Hal ini dikarenakan tidak ada arus yang mengalir kebeban. Setelah baterai mencapai titik minimumnya untuk dibebani pada menit ke-135, arus menuju beban akan mengalir. Arus charging mengalami penurunan secara signifikan karena beban dinaikkan sehingga baterai menjadi sumber tambahan. Baterai menjadi sumber tambahan 
dilihat dari nilai arus charging yang bernilai negatif yang menandakan baterai mengalami discharging. Pada menit ke-200 baterai berada sedikit dibawah titik minimumnya sehingga kontrol langsung menghentikan arus yang mengalir kebeban sehingga arus input sepenuhnya menjadi arus charging.

Berdasarkan rangkaian ekivalen baterai, baterai memiliki rugi-rugi. Rugi-rugi yang terjadi diakibatkan adanya tahanan dalam pada baterai. Nilai tahanan dalam pada baterai dapat dicari menggunakan metoda aftercharging[6]. Baterai yang digunakan pada kajian ini memiliki nilai tahanan dalam $0,79 \Omega$ setiap baterainya.

\section{KESIMPULAN}

Berdasarkan hasil percobaan dan analisis yang telah dilakukan pada penelitian ini maka dapat diambil kesimpulan berikut ini:

1. Pengaturan arus pengisian dan peluahan dapat telah berhasil dilakukan dengan batuan menggunakan metoda As (Ampere second).

2. Energi yang tersimpan pada baterai dapat dijaga agar tidak melebihi kapasitas maksimalnya $50 \mathrm{Ah}$ (180000 As).

3. Titik minimum kapasitas baterai dapat diatur sesuai keinginan. Pada kajian ini menggunakan titik minimum $11.67 \%$ dari kapasitas baterai $50 \mathrm{Ah}$ yaitu $5.835 \mathrm{Ah}$.

\section{DAFTAR PUSTAKA}

[1] Refdinal Nazir, Pengembangan Teknologi PLTPH Dalam Upaya Meningkatkan Daya Gunanya Sebagai Sumber Energi Listrik Rumah Tangga, Proceeding of National Seminar on Applied Technology, Science, and Arts ( $1^{\text {st }}$ APTECS), pp. 1114-1118 (2009).

[2] Alief P. B. S, Dedet C. R, dan Heri S., Monitoring Kinerja Baterai Berbasis Timbal untuk Sistem Photovoltaic, Jurusan Teknik Elektro, ITS. Surabaya (2013).

[3] Sunariaman, Perancangan Sistem Proteksi untuk Menghindari Kelebihan Kapasitas Baterai Menggunakan
Mikrokontroler ATMEGA 128, Tugas Akhir Jurusan Teknik Elektro UNAND, Padang (2013).

[4] Putra, Hermawan Permana. "Studi Karakteristik Pelepasan Muatan Baterai Lead Acid terhadap Variasi Beban RLC".Tugas Akhir Jurusan Teknik Elektro. UI. Depok (2010).

[5] Guo, Shen. "The Application of Genetic Algorithms to Parameter Estimation in Lead-Acid Battery Equivalent Circuit Models". University of Birmingham (2010).

[6] M. Coleman, C. K. Lee, dan W. G. Hurley. "An Improved Battery Characterization Method Using a TwoPulse Load Test". IEEE Trans. Energy Convertion, vol. 23, no. 2 (2008).

[7] Atsushi Tanaami \& Masayuki Morimoto, "On-line Estimation of SOH for LeadAcid Battery", PEDS, pp.1552-1555 (2009).

\section{Biodata Penulis}

Mochammad Rismansyah, lahir di Jakarta Indonesia, memperoleh gelar S1 jurusan Teknik Elektro Universitas Andalas pada Tahun 2014, dan saat ini bekerja di PT. PLN Pusat di Jakarta. 